\title{
Older Drivers in the Workplace: \\ How Employers and Workers Can Prevent Crashes
}

Older drivers at work bring extensive skills, knowledge, and experience built over the course of a lifespan. Research shows that older drivers are more likely than their younger counterparts to adopt safe behaviors such as wearing a seat belt and complying with speed limits. However, those age 55 and older have twice the risk of dying in a work-related crash than younger workers do.* One possible reason is that older persons are more likely to be injured if they are in a crash, and more likely to die if they are injured.

This fact sheet gives employers and workers information on age-related physical and mental changes that may affect older workers' driving. It is important to accommodate these changes so older workers may continue to contribute their expertise to the workplace under the safest conditions possible.

$\begin{gathered}\text { People } 55 \text { years } \\ \text { or older are a } \\ \text { growing group of } \\ \text { the U.S. population } \\ \text { that continues to } \\ \text { work and drive. }\end{gathered}$
$\begin{gathered}\mathbf{3 0 \%} \text { of Americans } \\ \text { will be } 55 \text { years or older. }\end{gathered}$
$\begin{gathered}\text { will be } 55 \text { years or older. } \\ \text { willion licensed drivers } 65 \text { years or older. }\end{gathered}$

Motor vehicle crashes account for $\mathbf{3 2} \%$ of all work-related deaths among workers age 55 or older.

Employers and workers share the responsibility for keeping older drivers safe at work.

Workers: Learn how to maintain your driving ability and safe driving habits as you grow older.

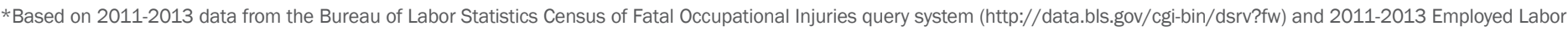
Force (ELF) population data. (http://wwwn.cdc.gov/wisards/cps/cps_estimates.aspx).

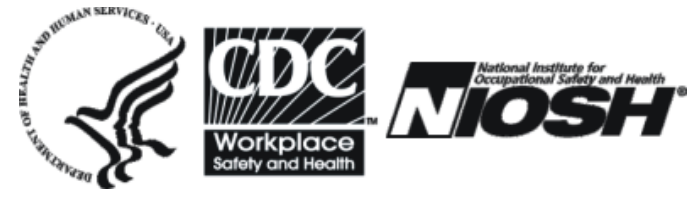




\section{How does aging affect driving ability?}

While older drivers are more likely to practice safe driving behaviors, both employers and workers should be aware that it is normal for physical and mental abilities to gradually decline with age - putting them at greater risk of dying if they are in a motor vehicle crash.

- Eyesight often worsens with age. Older eyes need more light and more time to adjust when light changes, so it can be hard to see clearly, especially at dawn, dusk, and night. Older drivers may become more sensitive to glare from headlights, street lights, and the sun.

- Peripheral vision - the ability to see to the side or up and down while looking ahead - often declines as people age, increasing their risk of crashes.

- Eye diseases such as cataracts, glaucoma, and macular degeneration become more common with age, making it harder for older drivers to read signs and see colors.

- Age-related hearing loss can make it harder to hear horns, sirens, and noises from cars, which warn of possible danger.

\section{- Several diseases and conditions can affect the ability to drive.}

Diabetes can make blood sugar levels too high or low, which can lead to drowsiness, dizziness, confusion, loss of consciousness, or seizures.

Arthritis can make joints swollen and stiff, limiting movement of the shoulders, hands, head, and neck. This can make it hard to grasp or turn the steering wheel, apply the brake and gas pedals, fasten a seat belt, or look for hazards.

Sleep apnea, a disorder in which breathing is briefly and repeatedly interrupted during sleep, can increase the risk of drowsy driving.

Parkinson's disease can cause a person's arms, hands, and legs to shake. This can affect balance and movement, diminishing a driver's ability to safely operate motor vehicle controls.

Other chronic diseases and the use of prescribed, over-the-counter, and multiple medications may interfere with sleep quality, increasing risk for drowsy driving.

\section{- Motor skills, essential for driving safely, can decline with age.}

Strength is vital for many driving tasks such as pressing down on a brake pedal.

Range of motion is important for fastening a seat belt or turning to look for vehicles and objects.

Flexibility allows the body and joints to move more freely, making it easier to observe the road from all angles. This can help with many driving tasks, including looking to the sides and rear of the car, steering, and parking.

Coordination helps the upper and lower body work together in situations such as simultaneously braking and turning.

- Mental abilities, including memory, attention span, judgment, and ability to make decisions and react quickly, are required for driving. These can gradually decline with age, making older drivers feel overwhelmed by signs, signals, pedestrians, and vehicles around them. 


\section{What can employers do}

\section{to prevent work-related crashes?}

\section{Employers: Set and enforce comprehensive motor vehicle driver safety policies.}

Require the use of seat belts at all times for all occupants.

\section{Plan and manage travel.}

Consider whether the work can be done without driving. Reducing the amount of driving workers do is the most effective way to prevent motor vehicle crashes.

$\square$ Set work schedules that allow workers to obey speed limits and follow applicable rules such as hours-of-service regulations.

Encourage supervisors and drivers to decide on the driver's route, destination, and travel schedule ahead of time.

$\square$ Set policies that allow drivers to consult with their supervisors to adjust driving hours if they have trouble seeing at night, and to stop driving if they are too tired or the weather is bad.

\section{Prevent distracted driving.}

$\square$ Ban texting and hand-held phone use while driving.

$\square$ Consider banning the use of hands-free phones.

$\square$ Require workers to pull over in a safe location if they must text, make a call, or use their hand-held device for other purposes such as looking up directions.

\section{Prevent drowsy driving:}

$\square$ Design work schedules that allow enough time off so workers can get adequate sleep.

Allow for breaks during the work shift.

$\square$ Allow workers to take a nap of less than 30 minutes or stop in a safe location if they are too tired.

$\square$ Promote a positive work environment to reduce job stress, which can affect sleep quality.

$\square$ Promote awareness of sleep disorders and other illnesses that may increase drowsiness.

\section{Resources \& Tools for employers:}

Work-related motor vehicle safety:

NIOSH Motor Vehicle Safety

www.cdc.gov/niosh/motorvehicle

Explore work-related motor vehicle safety

topics and resources.

Motor vehicle safety programs:

NIOSH Preventing Work-Related

Motor Vehicle Crashes

www.cdc.gov/niosh/docs/2015-111/

Tailor elements of a motor vehicle safety

program to address your company's needs.

Health and well-being:

NIOSH Total Worker Health ${ }^{\circledR}$

www.cdc.gov/niosh/twh/essentials.html

Identify resources to develop a comprehensive worker health, safety, and well-being program.

NIOSH Center for Productive Aging and Work www.cdc.gov/niosh/topics/productiveaging/ default.html

Promotes the safety of workers of all ages and their lifelong well-being.

Medications and Driving www.aaafoundation.org/resources/resources/ Encourage workers to use this resource from the AAA Foundation for Traffic Safety to learn how medications can affect their driving.

General information about older drivers:

National Center for Injury Prevention and Control (NCIPC)

www.cdc.gov/Motorvehiclesafety/Older_Adult_ Drivers/index.html

Understand how the risk of being injured or killed in a motor vehicle crash increases with age. 


\section{What can employers do}

\section{to prevent work-related crashes?}

\section{Employers}

\section{Prevent impaired driving:}

$\square$ Set policies that prohibit operating a vehicle under the influence of alcohol, illegal drugs, or prescription and over-the-counter medications that could affect the ability to drive safely.

$\square$ Give workers general information about the possible effects of prescription and over-the-counter medications on their driving.

\section{Promote worker safety, health, and well-being through} workplace policies, progirams, and activities.

$\square$ Incorporate topics such as exercise, healthy diet, and good sleeping habits.

\section{Assess driving ability.}

$\square$ Restrict driving based on assessment of actual driving ability, rather than general health status or an arbitrary age limit.

Make every effort to assign other job duties that don't require driving if a worker's ability to drive is affected temporarily or permanently.

\section{Promote safe driving.}

$\square$ Make drivers aware of advanced safety features available in their vehicles and their proper use.

$\square$ Provide "refresher" driving training that includes topics such as safedriving strategies, changes in road rules, regulations on distracted driving, and new vehicle safety features.

\section{Provide the following recommendations to workers to ensure a good vehicle fit.}

Maintain a clear line of sight over the steering wheel.

$\square$ Have at least 10 inches separating your chest from the steering wheel.

$\square$ Adjust your seat, seat belt, and head restraint to fit safely and comfortably.

Ensure easy access to gas and brake pedals.
National Highway Traffic Safety

Administration (NHTSA)

www.nhtsa.gov/Driving+Safety/

Older+Drivers

Find advice on how to talk with older drivers about safe driving.

National Institute on Aging (NIA) www.nia.nih.gov/health/publication/ older-drivers?utm_source $=20150629$ NewAP\&utm_medium=email\&utm campaign=ealert

Learn how to recognize if someone may be having trouble driving safely.

\section{American Occupational Therapy Association (AOTA) \\ www.aota.org/Conference-Events/Older- Driver-Safety-Awareness-Week.aspx \\ Listen to podcasts as part of AOTA's Older Driver Safety Awareness Week.}

\section{CarFit program \\ www.car-fit.org/}

Find the nearest CarFit event, where trained technicians and health professionals make sure drivers "fit" their vehicles properly for maximum comfort and safety.

Making sure the vehicle fits the driver:

\section{Association for Driver \\ Rehabilitation Specialists (ADED) www.aded.net/}

Search for a local driver rehabilitation specialist or a company that sells mobility equipment.

\section{My Car Does What} mycardoeswhat.org/ Learn about advanced vehicle safety features. 


\section{What can workers do to prevent crashes?}

\section{Workers: Take the following actions to stay}

safe while driving for work.

\section{Use your seat belt at all times and require passengers to do the same.}

$\square \quad$ Prevent distracted driving:

Do not text or use a hand-held phone while driving.

A Avoid using hands-free phones as much as possible.

P Pull over in a safe location if you must text or make a call.

$\square$ Do not drive under the influence of drugs or alcohol.

$\square \quad$ Talk with your doctor or pharmacist about the potential effects of your medications on driving:

Read medicine labels carefully and look for warnings and potential medication interactions.

$\square$ Do not drive if you feel lightheaded or drowsy.

$\square \quad$ Talk with your doctor about how your medical conditions may affect your driving.

$\square \quad$ Maintain good health.

Engage in regular physical activity two and a half hours per week.

Adopt a balanced diet of vegetables, grains, protein, fruit, and dairy.

- Talk with your doctor about what health screenings and exams you need.

Stay well-rested and alert by getting 7 to 9 hours of sleep each day.

See a doctor if you are often tired or sleepy.

\section{Get a thorough eye exam at least every 1 to 2 years.}

Make sure your prescription is up-to-date if you need glasses or contacts.

U Use a driving self-assessment tool to evaluate your driving:

S Seek help from your doctor or someone trained to do more intensive driving assessments if needed.

Take a driving refresher course to learn new driving strategies and recent changes in traffic laws.

\section{Resources \& Tools}

\section{for workers:}

Health and well-being:

Medications and driving www.aaafoundation.org/resources/resources

The AAA Foundation for Traffic Safety recommends resources to help you learn how medications can affect driving.

Sleep health:

\section{Your Guide to Healthy Sleep}

www.nhlbi.nih.gov/health/resources/sleep/

healthy-sleep

Get information about sleep disorders and

ways to improve sleep and alertness.

\section{Sleep.org}

www.sleep.org

Learn how sleep impacts your health.

Safe driving guidelines and tips:

Safe Driving and Lifelong Transportation agelab.mit.edu/safe-driving-lifelongtransportation

Focus on how to maintain safe driving skills.

American Automobile Association (AAA) www.roadwiseonline.org

Take the AAA Roadwise Review, an interactive self-assessment tool to check your physical strength and flexibility, clarity of vision, and skill in processing what you see while driving.

www.aaafoundation.org/useful-links

Get tips and resources to help you stay safe on the road.

\section{National Highway Traffic Safety} Administration (NHTSA) www.nhtsa.gov/Driving+Safety/Older+Drivers Discover advice on how to talk with other older drivers about safe driving.

National Institute on Aging (NIA) www.nia.nih.gov/health/publication/olderdrivers?utm_source $=20150629$ NewAP\&utm medium=email\&utm campaign=ealert Learn how to recognize if you or a loved one are having trouble driving. 


\section{What can workers do to prevent crashes?}

\section{Workers}

Talk to your supervisor if you are having difficulty with driving, as you may need to change your driving habits. Some strategies you may discuss are:

$\square$ Attend meetings by phone or video conference.

$\square$ Map out safe routes in advance to drive on well-lit streets with less traffic, clear signs, and easy parking.

\section{- Make necessary adjustments to your car to ensure a} good vehicle fit.

Maintain a clear line of sight over the steering wheel.

$\square$ Have at least 10 inches separating your chest from the steering wheel.

$\square$ Adjust your seat, seat belt, and head restraint to fit safely and comfortably.

Make sure you can easily reach the gas and brake pedals.

Seek advice from a professional trained in driver rehabilitation or adaptive technologies if chronic pain or decreased range of motion make it difficult to drive.

\section{Disclaimer}

Mention of any company or product does not constitute endorsement by NIOSH. Citations to websites external to NIOSH do not constitute NIOSH endorsement of the sponsoring organizations or their programs or products. Furthermore, NIOSH is not responsible for the content of these websites. All web addresses referenced in this document were accessible as of the publication date.

\section{Ordering Information}

To receive documents or other information about occupational safety and health topics, contact NIOSH:

Telephone: 1-800-CDC-INFO (1-800-232-4636) • TTY: 1-888-232-6348 CDC INFO: $\underline{\text { www.cdc.gov/info or visit the NIOSH website at www.cdc.gov/niosh }}$

For a monthly update on news at $\mathrm{NIOSH}$, subscribe to $\mathrm{NIOSH}$ eNews by visiting www.cdc.gov/niosh/eNews.

DHHS (NIOSH) Publication No. 2016-116 • March 2016
Insurance Institute for Highway Safety www.iihs.org/iihs/topics/t/older-drivers/ topicoverview

Learn about state laws on driver's license renewal for older persons.

General information about older drivers:

American Occupational Therapy Association (AOTA)

www.aota.org/Conference-Events/Older-DriverSafety-Awareness-Week.aspx

Listen to podcasts as part of AOTA's Older

Driver Safety Awareness Week.

myaota.aota.org/driver_search/

Search for a trained driving specialist who can assess your driving ability and recommend ways to accommodate age-related changes or disabilities.

\section{AARP}

www.aarp.org/home-garden/transportation/ driver safety/

Get driver safety resources including courses, recommendations for car selection, and tips on how to talk with older family members about their driving.

\section{CarFit program}

www.car-fit.org/

Find your nearest CarFit event, where trained technicians and health professionals make sure you "fit" your vehicle properly for maximum comfort and safety.

Making sure the vehicle fits the driver:

Association for Driver Rehabilitation Specialists (ADED)

www.aded.net/

Search for a local driver rehabilitation specialist or a company that sells mobility equipment.

\section{My Car Does What} mycardoeswhat.org/ Learn about your vehicle's advanced safety features. 